\title{
О НЕСОВПАДЕНИИ ОЦЕНОЧНЫХ ХАРАКТЕРИСТИК КРУПНЫХ СОБЫТИЙ И ГОСУДАРСТВЕННЫХ ДЕЯТЕЛЕЙ В НАШЕЙ СТРАНЕ У СМИ-ЭЛИТНЫХ И ОРДИНАРНЫХ МАСС РОССИЯН. ФАКТЫ И ИХ ОБЪЯСНЕНИЯ
}

\author{
Лившиц В.Н., Панов С.А.
}

Статья посвящена системному анализу ряда ситуаџий, суть которых в том, что в период 1992-2019 г2. в нашей стране было немало случаев, когда проводимые в стране крупные экономические или сочиальные мероприятия пользовались в наших СМИ оченкой, совершенно не совпадающей с той, которую озвучивали квалифичированные прямые массовые опросы нашего населения, проводимые непосредственно среди неэлитных граждан России Институтом Левады и др. В статье в качестве примера анализируются результаты рейтингового сочиологического исследования по выяснению наиболее популярных в России государственных деятелей, которое выявило в группе лидеров личность И. Сталина. В статье дается научная версия объяснения этого и других аналогичных парадоксов.

DOI: $10.20537 /$ mce2019econ08

В последние четверть века в период проведения трансформационных реформ в нашей стране, в ее экономике и социуме было немало случаев, когда проводимые в стране крупные экономические или социальные мероприятия пользовались в наших СМИ оценкой, совершенно не совпадающей с той, которые озвучивали квалифицированные прямые массовые опросы, проводимые относительно корректно непосредственно среди не элитных граждан России некоторыми, нашими примерно либерально-демократическими (по звучащему смыслу этих понятий, а не их интерпретации руководством ЛДПР) СМИ и социологическими Институтами - ВЦИОМ, Институтом Левады и др. Примером может служить осуществленное несколько лет тому назад (по нашему мнению, явно не самое мудрое) не спонтанное рейтинговое социологиче-

*Работа выполнена при частичной финансовой поддержке РФФИ (проект 17-06- 00041). 
ское мероприятие по выяснению наиболее популярных в России государственных деятелей. Неожиданно, по-видимому, для деятелей наших СМИ или, по крайней мере, вопреки прогнозам и желаниям их руководства, несмотря на всю интенсивную контрпропаганду в печати и на телевидении, в группе лидеров (а может быть и основным лидером) выявилась все же личность Иосифа Сталина, который в конечном итоге по результатам опросного голосования даже после соответствующей целенаправленной искусной рейтингопонижающей корректировки оказался, тем не менее, в числе лидеров - на третьем месте (на первом месте в конце концов, кажется, оказался Ю. Гагарин, а на втором А.В. Суворов). И эта «Сталинофилия», то есть его популярность среди неэлитных россиян, устойчиво сохраняется. Так, например, около полугода тому назад в самой многотиражной нашей околоцентральной газете «Московский Комсомолец» [1] на первой странице была опубликована статья «Сотни россиян хотят повесить Сталина», в которой говорится, что «настенные календари с отцом народов расхватываются как горячие пирожки...Тренд 2019 года: иметь дома или в офисе настенный календарь со Сталиным». Еще более говорящее название публикации в [2] известного журналиста-обозревателя МК Михаила Ростовского - «Сталин Суперстар» - тоже на первой же странице в той же газете чуть более трех месяцев спустя после отпразднования 16 января того же 2019 г. столетнего юбилея этой популярной газеты. В начале этой статьи приводится такая динамика результатов опросов населения - опроса «ЛевадаЦЕНТРА»: «Тех, кто относился к Иосифу Сталину положительно в 2001 г., было $38 \%$, а отрицательно, то есть причислял себя к противникам его 43\% граждан РФ; сейчас, то есть спустя 18 лет, таковых «за» - 51\%, а число антисталинистов растаяло до микроскопических 14\%. Правильнее при этом, наверное, будет более корректно не прямо, а косвенно интерпретировать результаты опроса, которые, на наш взгляд, отражают не столько отношение россиян к Сталину, сколько их отношение к тому, что происходит в стране». Возможно, что прав известный социолог Сергей Маркедонов, который тоже в МК пишет, что «на фоне коллапса ориентиров и разочарований отказа государства от социальных обязательств вкупе с жирующим чиновничеством Сталин становится символом - символом «порядка», «стабильности» и «справедливости».

В настоящее время аналогичная парадоксальная ситуация расхождения иерархических оценок складывается и по ряду других социальных проблем (см. ниже табл.1, в которой согласно [3] приведена часть 
результатов опроса 61 известных наших социологов - от писателя Адамовича до околоправительственного управленца Юргенса - в связи со столетним юбилеем происшедшей в октябре 1917 г. в России социалистической революции). Немало многотиражных СМИ у нас, да и многие представители наших властных структур не пожалели сил и времени, в том числе телевизионного (частного и государственного), чтобы представить это крупное историческое событие преимущественно в негативном плане, но массовые опросы рядовых граждан и в России, и за рубежом устойчиво говорят о позитивном в целом отношении к нему, и многих преимущественно позитивных его последствиях, хотя об их негативных и даже преступных тоже вспоминают. Такая ситуация нередко у нас проявляется применительно не только к дихотомической (позитивной-негативной) оценке крупных исторических событий или многих наших выдающихся личностей, но и в социальной, экономической и других сферах. Характерная важная деталь - граждане России, занимающие по тому или иному крупному социальному поводу противоположные позиции, при этом исходят из одних и тех же конкретных отдельных фактов и их совпадающих фактических значений количественных показателей, и чаще всего идентичных качественных оценочных (благожелательных или квалифицируемых как преступные или негативные) характеристик, но при этом в целом им дают противоположную системную оценку. Постараемся понять в чем тут причина, а затем предварительно повторно рассмотрим табл. 1, естественно далеко не полную, в которой приведен ряд примеров, о которых ведется речь.

Конечно, есть и такие исторические события, социальноэкономические проекты, государственные деятели, относительно которых дается более или менее однонаправленная оценка - или все вышеупомянутые участники опросов оценивают их позитивно, либо почти все негативно, например, оценка Бен Ладена, хотя это деятель не совсем российской истории, «не из нашего садика». Но более для нас интересен все же случай противоположных оценок, поэтому попытаемся дать объяснение этого феномена. Остановимся сначала на главной, по нашему мнению, причине возможностей проведения у нас подобных опросов и таких кардинальных расхождений, приведенных в табл. 1 мнений о рассматриваемых социально-экономических российских ситуациях. Но сначала отметим, что проведение подобных опросов - элемент демократизации, являющийся фактом положительного плана. Но главной причиной, по нашему мнению, является развал СССР, что является фактом негативным 
и даже катастрофическим для нашей страны. Может быть, правда, скорее причиной, по мнению ряда исследователей, которое нам близко, является по существу «материальное» и «нематериальное» предательство основной массой возникшего в период СССР высокообеспеченного своекорыстного партийно-чиновничье-торгового «сословия», в основном нередко законными-незаконными способами получавшими немалые привилегии и блага (лучшие должности и более высокие доходы и зарплаты , возможности выезда за рубеж, через «черный ход» и без очереди дефицитные продовольственные и непродовольственные товары, недоступные остальным ординарным внесословным россиянам, и т. д.). Но немалое значение на развал Союза оказало и их «нематериальное» - идеологическое предательство, когда реально проводилась тройная политика их членами по отношению к декларируемым, в том числе и среди многих других граждан, но не исполняемых ими самими ценностей и принципов социалистического толка (при этом реально думали одно, верили в другие социально-экономические принципы, а в практических своих действиях опирались на третьи, несовместимые часто с предыдущими, принципы личного корыстолюбия и накопления личного или семейного богатства). Надо оговориться, что когда в этом контексте упоминается о «сословии», то речь не идет о самой верхней его иерархии (членах и кандидатах в Политбюро ЦК КПСС, первых лицах в руководстве Правительством и государством и др.). Потому, что их даже в период неолиберальных реформ после 1992 года наши суперангажированные на негатив по отношению к тому, что было в советское время, СМИ и другие властные структуры не обвиняли в том, что они лично разворовывали страну или положили на свой счет в российские или зарубежные банки миллиарды, или скупали в Лондоне дворцы и т. д. - то есть действовали так, как, фактически поступали при правлении современной Россией их наследники - нынешние олигархи и оказавшиеся у управлении страной многие наши неолибералы - их, имеющих сегодня каждый у нас в России, по данным журнала ФОРБС личное состояние более миллиарда долларов, более ста (по миллиардерам третье место в мире после США и Китая). И это все на фоне десятков миллионов фактически и официально (по данным Росстата) нищенствующих россиян, которые появились после развала СССР, о чем, и о причинах этого, в том числе и причин развала СССР, убедительно пишется и в ряде зарубежных публикаций $[4,5]$. Но вернемся к анализу случаев неидентичности оценок, совокупность которых для удобства системного анализа приведена сразу в табл. 1. 
Таблица 1. Предполагаемые оценки крупных исторических событий или выдающихся личностей представителями СМИ-властных структур и масс ординарных граждан.

\begin{tabular}{|c|c|c|c|}
\hline $\begin{array}{l}\text { № } \\
\text { П/ח }\end{array}$ & Содержание вопроса & $\begin{array}{l}\text { Предполагаемое от- } \\
\text { ношение к ним пред- } \\
\text { ставителей СМИ- } \\
\text { властных структур }\end{array}$ & $\begin{array}{l}\text { Предполагаемая } \\
\text { оценка представите- } \\
\text { лями масс ординар- } \\
\text { ных граждан }\end{array}$ \\
\hline 1 & $\begin{array}{l}\text { Отношение к Октябрьской } \\
\text { революции }\end{array}$ & В основном негативное & В основном позитивная \\
\hline 2 & $\begin{array}{l}\text { Оценка для России в це- } \\
\text { лом 80-летнего периода } \\
\text { советской власти в стране }\end{array}$ & В основном негативное & В основном позитивная \\
\hline 3 & $\begin{array}{l}\text { Отношение к Иосифу Ста- } \\
\text { лину и его деятельности }\end{array}$ & В основном негативное & $\begin{array}{l}\text { В основном позитив- } \\
\text { ное }\end{array}$ \\
\hline 4 & $\begin{array}{l}\text { Отношение к Борису Ель- } \\
\text { цину как Президенту России }\end{array}$ & В основном & В основном негативное \\
\hline 5 & $\begin{array}{l}\text { Отношение к проведенной } \\
\text { приватизации госсобст- } \\
\text { венности }\end{array}$ & В основном & В основном негативное \\
\hline 6 & $\begin{array}{l}\text { Оценка эффективности ме- } \\
\text { роприятия «футбол 2018» }\end{array}$ & ивная & ивное \\
\hline 7 & $\begin{array}{l}\text { Отношение к продлению } \\
\text { пенсионного возраста вы- } \\
\text { хода на пенсию }\end{array}$ & В основном позитивное & В основном негативное \\
\hline 8 & $\begin{array}{l}\text { Отношение к большинст- } \\
\text { ву мегапроектов }^{\dagger}\end{array}$ & В основном позитивная & В основном негативное \\
\hline 9 & $\begin{array}{l}\text { Отношение к действую- } \\
\text { щему с } 1992 \text { года по суще- } \\
\text { ству неолиберальному } \\
\text { Правительству РФ }\end{array}$ & В основном позитивное & В основном негативное \\
\hline 10 & $\begin{array}{l}\text { Отношение к кадровой по- } \\
\text { литике нашего государства }\end{array}$ & В основном позитивное & В основном негативное \\
\hline 11 & $\begin{array}{l}\text { Отношение к действую- } \\
\text { щей системе оплаты труда }\end{array}$ & В основном позитивное & В основном негативное \\
\hline 12 & $\begin{array}{l}\text { Отношение к платности } \\
\text { социальных услуг }\end{array}$ & В основном позитивное & В основном негативное \\
\hline
\end{tabular}

\footnotetext{
* Обычно противники ее даже революцией не считают и называют то большевистским переворотом, то заговором, то чем то еще уничижительным.

Болышая Москва, Мост на о. Русский и др.

‡ Особенно относительно коммерциализации здравоохранения и образования
} 
Таблица 1. Продолжение.

\begin{tabular}{|c|c|c|c|}
\hline 13 & $\begin{array}{l}\text { Отношение к распаду Со- } \\
\text { ветского Союза }\end{array}$ & $\begin{array}{l}\text { У многих представите- } \\
\text { лей современных не- } \\
\text { олиберальных СМИ, } \\
\text { предпринимателей, ру- } \\
\text { ководства частных и } \\
\text { госкомпаний и других } \\
\text { «псевдодемократиче- } \\
\text { ских» кругов нередко } \\
\text { вполне позитивное }\end{array}$ & $\begin{array}{l}\text { В основном негатив- } \\
\text { ное, объясняемое раз- } \\
\text { рушением экономики } \\
\text { страны, резким сниже- } \\
\text { нием уровня жизни } \\
\text { большинства россиян, } \\
\text { чрезмерной дифферен- } \\
\text { циацией доходов у раз- } \\
\text { личных групп россиян }\end{array}$ \\
\hline 14 & $\begin{array}{l}\text { Отношение к арестам вы- } \\
\text { сокопоставленных чинов- } \\
\text { ников (Депутатов Феде- } \\
\text { рального Собрания - Гос- } \\
\text { думы и Совета Федера- } \\
\text { ции) [6] }\end{array}$ & & $\begin{array}{l}\text { Аресты - это не акт } \\
\text { справедливости, а } \\
\text { борьба этих чинов- } \\
\text { ников за передел } \\
\text { сфер влияния (40\% } \\
\text { опрошенных). Аре- } \\
\text { сты вызывают раз- } \\
\text { дражение у населе- } \\
\text { ния (14\%) }\end{array}$ \\
\hline 15 & $\begin{array}{l}\text { Отношение к полноте ука- } \\
\text { зания в Декларациях выс- } \\
\text { шими госчиновниками } \\
\text { своих доходов [6] }\end{array}$ & & $\begin{array}{l}\text { «Все» (3\% опрошен- } \\
\text { ных), «чиновники ука- } \\
\text { зывают меньшую ве- } \\
\text { личину» }(40 \%), \text { «ни- } \\
\text { чтожно малую» }(37 \%) .\end{array}$ \\
\hline
\end{tabular}

На основании анализа позиций этой таблицы с помощью довольно надежной, по нашему мнению, официальной информации органов государственной статистики нами предлагается следующий относительно простой и ясный ответ на этот непростой вопрос «Почему так кардинально расходятся оценки?». Ответ такой: потому, что, по крайней мере, кто-то один или оба из упоминаемых пар оценщиков методологически оценивают неправильно. Рассмотрим это на примере отношения к личности И.В. Сталина и (или) отношения к Октябрьской Революции. Обычно те, кто характеризует их для России резко негативно, упоминают о преступлениях власти в 20-40-е годы, в результате которых пострадали (в том числе погибли) сотни тысяч (иногда их число увеличивают до нескольких миллионов и даже их десятков) невинных людей, и напоминают, что страна в первые дни войны потерпела ряд сокрушительных поражений, в том числе и потому, что армия была репрессиями 
30-х годов обезглавлена, в конце сороковых годов были опять массовые репрессии невинных граждан (в том числе наказание путем выселения в Сибирь и Среднюю Азию ряда южных народов) и т. д. Перечислять все преступления, негативные решения, ошибки, которых, по-видимому, могло и не быть, если бы не было феноменов деятельности И.В. Сталина (например, вместо него был бы В.И. Ульянов или хотя бы Николай Бухарин) и Октябрьской Революции, можно долго. Одновременно с этим противники Сталина и Октябрьской Революции для объективности перечисляют и немалые их заслуги (индустриализация страны, в конечном итоге победа в войне и др.). Затем на основе суммирования отдельно позитивных и отдельно негативных компонентов подводят псевдобухгалтерский итог, который у них часто получается негативным. Мы полагаем, что упомянутая нами выше методологическая ошибка и заключается в неправомерном применении этой бухгалтерии, игнорирующей то, что речь идет об оценке мирового уровня события и государственного деятеля, а в таких случаях псевдобухгалтерский подход некорректен. Доказано теоретически, политэкономически и экономико-математически на динамических моделях [7], что такой подход годится только для оценки малых мероприятий, событий, личностей, социально-экономических процессов и т. д., а здесь методологически надо применять подход, принятый при корректной оценке эффективности крупных инвестиционных мегапроектов [8-12] путем сравнения (на основе методологии системного анализа) ситуации с проектом и без проекта. И при этом все уже в смысле оценки выглядит совсем иначе «с проектом», т.е. при совершенной революции и Сталинском руководстве оказалось возможным то, что реально и произошло: индустриализация, прекрасное образование ранее неграмотного народа, победа в войне. А «без проекта», т.е. без революции думается, все это было бы невозможно, и вполне возможно, что судьба России была бы похожа на судьбу другой Великой Державы - Франции. И тогда уже больше подходит то, что «сняв голову о волосах, т.е. десятках миллионов жизней, уже бессмысленно плакать. Тогда речь шла бы о всей нашей стране, нескольких сотнях миллионов ее жителей, их жизнях и свободе. Тем более, что в последнее время (после 1992 г.) появилось много новой информации (или дезинформации), которая сильно смещает оценочные акценты. Например, прозвучала недавно (в том числе и в печати, и по телевидению) такая мысль, что после разгрома немцев под Москвой в 1941 г. фюрер Германии Гитлер в конце декабря принял решение (и пе- 
редал его на исполнение руководству СС и СД), чтобы (в целях экономии продовольственных ресурсов, значительный дефицит которого возник в Германии якобы из-за ее прекращения в нарушение нашей страной условий договора Молотова-Розенберга регулярного снабжения продовольствием из СССР), мол, для сокращения числа «едоков», кроме проведения кампании холокоста, то есть уничтожения миллионов евреев, дополнительно также прекратить кормить все остальное неарийское население на оккупированной территории, то есть для начала фактически уничтожить еще примерно около 30 млн наших людей. Естественно, что затем бы дошла очередь и до других. Понятно также и то, что на этом, особенно после поражения под Сталинградом, фашистские «аппетиты» экономии продовольствия могли только возрасти. Таким образом, по «гамбургскому счету» речь в варианте «без проекта» идет о жизнях всего населения СССР, то есть не о нескольких миллионах, а о трехстах миллионов человек, которые могли быть уничтожены гитлеровской военно-партийно-идеологической машиной. Вряд ли следует сомневаться в том, что такая перспектива — с проектом фюрера — не реализовалась только потому, что советский народ разрушил планы фашистского государства и его руководства, что Октябрьская Революция и позитивные компоненты деятельности нашего Генсека, наличие которых также никем не отрицаются, создали предпосылки для возможного сильного укрепления обороноспособности нашей страны (проведения индустриализации, многоуровневого высококачественного образования населения СССР, создания мощного антигитлеровского блока СССР - США, Англия и некоторые другие государства) и, в конечном итоге, для реализации победы над немецким фашизмом. О позитивной значимости и в этом плане Октябрьской Революции для населения не только нашей страны, но и практически стран всего мира, ее влияния на уровень жизни, условия занятости населения и др. очень убедительно говорили в своих выступлениях на состоявшемся 2-5 ноября 2017 г. в МГУ и СПбГУ Международном Форуме «Октябрь. Революция. Будущее» приехавшие на него представители нескольких десятков стран всех континентов, причем особенно многочисленная делегация была из КНР, которая неоднократно подчеркивала позитивное влияние дружбы с СССР и его помощи на развитие Китая, которой, естественно бы не было, если бы Октябрьская Революция не состоялась и СССР не был бы построен и защищен. Да и многие другие выступавшие там представители «вполне западных и вполне капиталистических стран с рыночной 
экономикой» подчеркивали, что одним из важных результатов Октябрьской Революции было то, что она сильно напугала реальных хозяев «дикого капитализма» и они сочли предпочтительным по собственной инициативе изменить (в данном случае речь идет, прежде всего, о XX в.) направление тренда уровня жизни наемных тружеников с падающей динамики на растущую. Практически это вызвало к жизни реализацию многих социально-экономических мероприятий, в том числе и таких принципиальных как введение и контроль за соблюдением практически во всех странах с развитой рыночной экономикой антимонопольных законов; далее было системно введено законодательство, в значительной мере нормализующее условия женского и детского труда, 8-часовый рабочий день для взрослых и др.; немаловажное значение в этой связи имело значительное расширение сферы деятельности и усиление активности производственных профсоюзов, а также других ассоциаций, без согласования с которыми капитал уже не мог бесконтрольно, как это было ранее (см., например, книгу Максима Горького «Мать» и др.), негативно вмешиваться в решение вопросов труда и зарплаты, увольнения и ареста недовольных трудящихся и т. д. Вряд ли думается также, что эти реальные факты, связанные с переходом на Западе от хозяйственных отношений, свойственных «дикому капитализму», к адекватным отношениям следующего века при последующих индустриальном и постиндустриальном развитом рынках дают основания обоснованно утверждать, как это нередко делали некоторые наши российские ретивые неолиберальные реформаторы после 1991 г., что «Марксизм, утверждавший об абсолютном и относительном обнищании в перспективе рабочего класса, как политэкономическая теория устарел и его важнейшие положения просто ошибочны». Представляется, что это не так, и многое, что было написано К.Марксом и Ф.Энгельсом («Коммунистический Манифест 1848 года» и ряд последующих работ) непосредственно по современному им капитализму, имеет и для нас и многих других стран и теоретическую и практическую ценность. Тем более что рост производства, исчисляемый по динамике ВВП, в Китае фактически почти все годы рыночных реформ после 1990 г. был не менее 8-9\% годовых, да и сейчас держится на рекордном уровне. К сожалению, у нас в России (см. $[4,9-11,13,14])$ реформы проводились иначе чем в Китае - по неолиберальной концепции методом шоковой терапии, и построенная в России в последние почти тридцать лет хозяйственная система является [12, с.117], вопреки обещаниям реформаторов, по существу не нормальной стацио- 
нарной эффективной рыночной системой ${ }^{*}$, а в значительной степени аномальной нестационарной неэффективной псевдорыночной. Да и вообще она во многих своих важных чертах сродни изучавшемуся классиками марксизма «дикому капитализму». Недаром же многие годы бывший директором Института Экономики РАН, а ныне его Научный Руководитель Р.С. Гринберг, охарактеризовал [18, с.78] следующим образом функционирование построенного в России в период реформ неолиберального гибрида российско-европейского квазирыночного нестационарного и неэффективного общества: «Наша жизненная философия стала простой - «спасайся, кто может. Это значит, что ты сам должен искать себе средства на пропитание. Обогащайся как можешь! У нас нет никакой коррупции, просто все учреждения стали коммерческими - от роддома до морга». И итоги у нас другие, чем в Китае - тоже рекордные, но не в смысле позитива, а негатива.

В одной из предыдущих опубликованных работ [19] в самом ее названии он посетовал: «Мы понадеялись на рынок, а он погубил все, что не приносит быстрых денег» и через два года тоже в названии очередной публикации подытожил [20]: «Это трагедия, когда россияне думают, что кто богаче - тот вор, а кто беднее - лох». Таким образом, предпринятая нашими неолиберальными реформаторами в 90-е годы прошлого века контрреволюционная попытка ухода с пути развития нашей страны, предопределенного Октябрьской Революцией и осуществлявшегося последовательно, хотя нередко и преступно Генсеком И.В. Сталиным в течение последующих после смерти Ленина тридцати лет, не дала ординарным, т.е. не находящимся у власти россиянам ни свободы, ни справедливости, ни тем более системного повышения материального уровня их жизни. Поэтому нам представляется достаточно логичным считать, что именно этими, упомянутыми выше системнопроектными соображениями в основном определяются результаты народного голосования, давшие заслуженную весьма высокую позитив-

\footnotetext{
*Под которой имеется в виду достаточно четко определенная в учебниках по макроэкономике [15,16] и специальных научных монографиях [8-11,14,17] экономическая макросистема с растущим во времени трендом позитивных индикаторов роста производства и уровня жизни (ВВП на душу населения, душевые доходы по ППС и др.) и различными их циклическими финансовыми колебаниями - краткосрочными циклами Китчина, Митчела и Жюгляра продолжительностью 36 месяцев - 10лет; среднесрочными циклами Саймона Кузнеца с периодом 18-20 лет и долгосрочными циклами конъюнктуры Н.Д.Кондратьева с периодом 48-53 года.
} 
ную оценку деятельности бывшего Генсека ВКП(б) и КПСС и его общественного рейтинга, несмотря на многие признаваемые и его противниками, и его защитниками тяжелые преступления в периоды репрессий $30-\mathrm{x}-40$-х годов XX в.

Что же касается упомянутых инсинуаций об устарелости марксизма как политэкономической теории, аргументировано это отрицает не ктонибудь, а сам гуру рыночной экономики [21], автор знаменитой монографии «Новое индустриальное общество». Он, хотя, как пишется в [22] «Гэлбрейт никогда не относился к марксистам, но он высоко ценил труды Маркса и не раз ссылался на них в своих книгах, подмечал, например, что никто, кроме Маркса и марксистов, не предвидел, что экономика гигантских корпораций станет сутью экономической системы». Изучение в советское время основ марксизма во всех вузах, в том числе и обязательное изучение ряда монографий и статей И.В. Сталина, повидимому, также определенным образом отразилось на качестве опросного рейтинга Октябрьской Революции и ее Генсека.

В свете вышесказанного нам думается, что более логично считать, что именно упомянутыми выше соображениями, в основном определяются результаты народного голосования. Между тем последние три десятилетия сожалению у нас реформационные процессы шли и идут скорее в противоположном чем в Китае направлении - темп роста ВВП последние годы и в обозримой перспективе в разы меньше, чем у восточного соседа, падает уже несколько лет и реальная заработная плата и реальные доходы у основной массы россиян. Одновременно в [23] отмечается: «Несмотря на спад в экономике, в прошлом году выросло количество богатых граждан, фиксирует статистика Федеральной налоговой службы. Так количество налогоплательщиков, задекларировавших за 2014 г. доход более 1 млрд рублей, возросло на 5.8\% - с 292 до 309 человек. Выросло и количество миллионеров. Так количество поданных налоговых деклараций с задекларированным доходом от 1 млн до 10 млн рублей выросло на 13\% и составило 453 тыс. Увеличилось и количество мультимиллионеров: заработавших в прошлом году от 500 млн до 1 млрд рублей стало на $6.6 \%$ больше - 453 человека. «Средний» класс, который задекларировал доход от 10 млн до 500 млн рублей, почти не изменился: было подано 23.5 тыс. деклараций, что на $1 \%$ больше аналогичного показателя за 2013 г.». Дополнительным аргументом является авторитетное мнение главного экономиста Института фондового рынка и управления М. Беляева о дифференциации уровней заработной 
платы наемных работников: «Экономика России переживает сложные времена и, прежде всего, хозяйственные невзгоды испытывают на себе, как водится, рядовые граждане. Их доходы сокращаются, а раскрутившаяся инфляция опустошает карманы наших соотечественников. А вот топ-менеджерам госкомпаний волноваться не о чем. Их кошельки не только «не похудели», а даже пополнились» [24].

Как здесь не вспомнить о существовании в нашей стране некоего «коэффициента Краузе», равного 2. Герой социалистического труда Краузе Геннадий Леонидович командовал тогда одним из лучших автокомбинатом №1 Главмосавтотранса, включенным в эксперимент Косыгинской реформы. А коэффициент 2 означал, что месячная зарплата при успешной его работе была равна удвоенной среднемесячной зарплате водителей комбината, причем их производительность труда при этом тоже резко выросла. Конечно, неравенство доходов сохранялось существенное, но далеко не такое вопиющее как при зарубежном или нашем родном российском вариантах капитализма, где неравенство в несколько порядков, зашкаливает. Вывод о том, что такой коэффициент может стать регулятором разумной, справедливой и эффективной экономики, явно свидетельствует о достоинствах ее социалистического варианта по сравнению с существующими капиталистическими образцами. Это наше утверждение неплохо гармонирует с известным мнением Джона Мейнарда Кейнса, приведенным в [25]: «Декадентский интернациональный, но индивидуалистический капитализм, в руках которого мы находимся после Первой мировой войны, успехом не увенчался. Он не разумен, не красив, не справедлив, не добродетелен. И не дает желаемого результата. Короче он нам не нравится...». Гармонирует оно и с высказанным в последнем интервью нобелевского лауреата Жореса Алферова [26]: «Сто лет тому назад мы создали благодаря гению Владимира Ильича Ленина уникальный пример в истории мировой цивилизации перешли к строительству социалистического общества. Я в Госдуме читал лекцию, которая называлась так: Альберт Эйнштейн: «социализм и современный мир». Альберт Эйнштейн в 1949 г. написал статью «Почему социализм?», в которой он с присущей ему абсолютной логикой и в общем простыми средствами показал, что выход, вообще говоря для мировой цивилизации - это социалистическое общество, плановое ведение хозяйства, обобществление собственности, прежде всего в промышленности, в крупных отраслях. То, что мы сделали, мы сделали 
ужасную вещь - мы, как говорится, ликвидировали величайшее достижение мировой цивилизации».

Как нам, авторам статьи, хочется думать, мы дали объяснение (или хотя бы его новый вариант) с позиций интересов населения России сути и причин парадоксального несовпадения оценок крупных российских событий и личностей. Суть его, повторимся, в том, что псевдобухгалтерский подход путем сравнения плюсов и минусов, по-видимому, справедлив, когда корректно применение классического принципа «методологического индивидуализма», позволяющего все виды полезных благ и «вредных» антиблаг сводить к совместимым (следовательно, алгебраически суммируемым) индивидуальным благам. В этих условиях многие сомнительные теоретические положения становятся справедливыми и, следовательно, приемлемыми. В частности, можно согласиться и с положением, названным автором монографии [27]. Согласно М. Блэку «гильотина Юма»: «невозможно из того, что есть, вывести то, что должно быть», а также с тем, что часто приемлемо классическое утверждение, известное кажется еще со времен Давида Юма и Адама Смита в XVIII в., «что если ценность чего-либо для каждого индивидуума в коллективе равна нулю, то и ценность всего этого чего-либо для всего коллектива тоже может быть ноль и только ноль» [27, с.178]. Между тем как было показано уже в настоящем веке в ряде фундаментальных работ-монографий [27-31] все это сомнительные положения, которые с некоторым основанием можно отнести к нетрадиционным, то есть не всегда указываемым в студенческих учебниках по микроэкономике провалам рынка.

Из указанных положений, если их принять, логически и математически следует, что фактически существуют только индивидуальные сводимые и, следовательно, допускающие алгебраическое суммирование блага. Из созданной же теми же авторами [28] теории «экономической социодинамики» вытекает некорректность приведенных положений и в ряде, если не большинстве ситуаций, необходимость и полезность признавать наряду с частично сводимыми индивидуальными благами и интересами существование также несводимых коллективных (групповых) благ и интересов, причем как в целом по коллективу, так иногда частично по некоторым группам. Соответственно, это надо учитывать и при решении ряда смежных важных теоретических и прикладных проблем. Например, в общей теории эффективности и при оценке эффективности конкретных инвестиционных проектов, где, в частности, при оценке эффективности инвестиционных программ, то есть групп 
инвестпроектов, связанных и несвязанных между собою, нередко нельзя допускать элементарную алгебраическую сводимость результатов проектов, тем более смешивать разные виды эффективности проектов, например, коммерческую и общественную, о которых речь шла выше. Именно реальное наличие множества полезных благ, сводимых и несводимых, несовершенство «незримой руки рынка» является, по нашему мнению, существенной причиной возможного иерархического несовпадения приведенных в табл. 1 оценок.

\section{СПИСОК ЛИТЕРАТУРЫ}

1. Сотни россиян хотят повесить Сталина // Московский комсомолец, 21.11.2018. №255 (27839). c.1.

2. Сталин Суперстар // Московский комсомолец. 17.04.2019. №82(27954)

3. К 100-летию Русской революции // Журнал «Мир перемен». №4. 2017.

4. Стиглии Дж. Цена неравенства. Чем расслоение нашего общества грозит нашей экономике. М.: ЭКСМО. 2015.

5. Коти Д.М., Вир Ф. Путь от Горбачева к Путину. Гибель советской системы и Новая Россия. Пер. с англ. Под ред.И.Ю. Готлиба. М.- Едиториал УРСС. 2013. (Будущая Россия. №23).

6. Попов Д. Россиян перестали радовать аресты чиновников // МК 08.05.2019. №96 (27968). c.1-2.

7. Лурье А.Л. О математических методах решения задач на оптимум при планировании социалистического хозяйства. М.: Наука, 1964.

8. Виленский П.Л., Ливщии В.Н., Смоляк С.А. Оценка эффективности инвестиционных проектов. Теория и практика. М.: Поли Принт Сервис, 2015.

9. Лившии В.Н., Лившии С.В. Системные аспекты методологии оценки эффективности инвестиционных проектов // Оценка эффективности инвестиций. Вып.2. М.: ЦЭМИ. 2002. с.62-77.

10. Лившии В.Н., Лившии С.В. Оценка эффективности инвестиционных проектов в стационарных и нестационарных макроэкономических условиях // Экономика строительства. 2003. №5. с.2-22.

11. Лившии В.Н., Лившии С.В. Системный анализ нестационарной экономики России (1992-2009): рыночные реформы, кризис, инвестиционная политика. М.: Поли Принт Сервис, 2010.

12. Лившии В.Н. Системный анализ рыночного реформирования нестационарной экономики России. 1992-2013. М.: ЛЕНАНД, 2013. 
13. Аганбегян А.Г. Советская экономика - взгляд в будущее. М.: Экономика, 1988.

14. Лившиц В.Н., Лившии С.В. Макроэкономические теории, реальные инвестиции и государственная российская экономическая политика. M.: URSS, 2008.

15. Самуэльсон П.А., Нордхаус В.Д. Экономика. Пятнадцатое издание. М.: Бином Кио-Рус, 1997.

16. Макконнелл К.Р., Брю С.Л. Экономикс: Принципы, проблемы и политика: в 2 т. Пер. с англ. 13-го изд. М.: ИНФРА-М, 2001.

17. Костюк В.Н. Нестационарная экономика. Влияние роста сложности на экономическое развитие, 2004.

18. Гринберг Р.С. Свобода и справедливость. Российские соблазны ложного выбора. М.: Магистр. ИНФРА-М, 2012.

19. Гринберг Р. Мы понадеялись на рынок, а он погубил всё, что не приносит быстрых денег // Комсомольская правда. № 181 (28404). 02.12.2009.

20. Гринберг $P$. Это трагедия, когда россияне думают, что кто богаче - тот вор, а кто беднее - лох // Комсомольская правда. 22.09.2011.

21. Гэлбрейт Дж. Новое индустриальное общество. М.: Прогресс, 1969.

22. Цаголов Н.А. Курс политической экономии \В двух томах. 3-е изд., переработ. и доп. М.: "Экономика", 1973-1974 гг.

23. Баязитова А. Ограбление народа в интересах олигархии продолжается // «Известия». №134 (29380). 24.07.2015. с.1.

24. Беляев М. «Зарплатная пропасть» России. Топ-менеджеры Госкомпаний зарабатывают в 150 раз больше рядовых служащих. //МК №31 (26.743). 16.02 2015. c.1.

25. Кейнс Дж.М. Теория занятости, процента и денег. М.: Прогресс. 1978.

26. Алферов Жорес о микроэлектронике, величии СССР и ценном аналоге Нобелевской премии. Интервью 06.11.2018 Андрею Угланову.

27. Рубинштейн А.Я. Рождение теории. Разговоры с известными экономистами. М.: Экономика. 2010.

28. Гринберг Р.С., Рубинштейн А.Я. Экономическая социодинамика. М.: Экономика, 2000.

29. Гринберг Р.С., Рубинштейн А.Я. Основания смешанной экономики. Экономическая социодинамика: М.: Институт Экономики РАН, 2008.

30. Рубинштейн А.Я. Экономика общественных преференций. СанктПетербург: Алетейя, 2008.

31. Рубинштейн А.Я. Теория опекаемых благ. Санкт-Петербург: Алетейя, 2018.

32. Блауг М. Экономическая мысль в перспективе. М.:Дело, 1994. 


\section{ON THE DIFFERENCE IN GREAT EVENTS' AND POLITICAL LEADERS' EVALUATION BY THE MEDIA-ELITES AND COMMON CITIZENRY IN RUSSIA. FACTS AND EXPLANATIONS}

\section{Livchits V.N., Panov S.A.}

The article uncovers the system analysis of an array of situations dealing with the period of 1992-2019 in Russian history, when grand-scale economic and social projects conducted in our country were assessed by the media quite differently than by non-elite Russian citizens that was revealed by direct mass surveys of Levada's Institute. In this article by the way of example the results of rating sociological survey targeted to identify the most popular government leaders were analyzed, which revealed J.Stalin to be one of the leaders. Therefore the article gives the scientific approach to explain this and some other analogous paradoxes. 